\title{
FOREIGN EXCHANGE CONTROLS IN A BLACK MARKET ECONOMY*
}

\author{
Jeremy GREENWOOD \\ University of Western Ontario, London, Ont., Canada N6A SC2 \\ Rochester Center for Economic Research, Rochester, NY 14627, USA \\ Kent P. KIMBROUGH \\ Duke University, Durham, NC 27706, USA
}

Received July 1985, final version received August 1986

\begin{abstract}
An investigation of the impact of foreign exchange controls in a black market economy is undertaken within the context of a choice-theoretic cash-in-advance general equilibrium model. While such controls may improve a 'distortion-free' economy's trade balance and balance of payments they are found to increase the domestic price of imports and lower the country's welfare. The ramifications of black market for economic welfare turn out to be ambiguous, depending crucially on the government's reaction to the leakage of foreign exchange into the economy via illegal activity.
\end{abstract}

\section{Introduction}

The use of foreign exchange controls is widespread in today's world economy. While foreign exchange controls are instituted for a wide variety of reasons some commonly stated objectives are to improve the trade balance, reduce dependence on imports and redistribute income toward the factors of production used intensively in import-competing industries, benefit the balance of payments or exchange rate, and to insulate the domestic economy from the vagaries of world markets. Whatever the rationale for such controls, it is important to examine their effects from the perspective of positive economics.

The artificial scarcity of foreign exchange induced by controls often drives the value of foreign exchange significantly above the price at which it can be officially purchased. This divergence between the user value of foreign exchange and its official price creates incentives for arbitragers to emerge who divert funds away from the low cost official foreign exchange market to

\footnotetext{
*Helpful comments from Slobodan Djajić and an anonymous referee are gratefully acknowledged. This research has been supported by the Social Sciences and Humanities Research Council of Canada.
} 
higher value users. Thus in economies with foreign exchange controls in effect black markets more often than not emerge. Consequently, it seems likely a meaningful analysis of the effect of foreign exchange controls on an economy's general equilibrium should formally incorporate a black market into the modelling apparatus.

An examination of the impact of foreign exchange controls in a black market setting is undertaken here. The investigation utilizes the choicetheoretic cash-in-advance general equilibrium model developed by Helpman (1981) to evaluate alternative exchange rate institutions. This approach has been chosen since it highlights, within the context of a paradigm which provides a careful articulation of the role of money, how the imposition of foreign exchange controls limits the opportunity sets facing private agents and affects their decision-making. The incentive for a black market to develop in order to evade the restrictions placed on private agents' trading opportunities, and the nature of its operation, can be clearly seen. It is then easy to infer the general equilibrium ramifications of foreign exchange controls in the presence of a black market. The consequences of foreign exchange controls for the macro-economy's general equilibrium, or for such variables as the domestic terms of trade, the level of imports, the trade balance, and the balance of payments are addressed. Since the model's foundations rest directly on specifications of individuals' tastes and endowments the welfare implications of exchange controls and black markets are readily assessed, as is done.

Finally, it should be mentioned that foreign exchange controls have been discussed recently within the context of cash-in-advance general equilibrium models by Greenwood and Kimbrough (1986) and Kowalczyk (1985). Also, in the real trade literature smuggling has been addressed within the standard static two-sector real trade model by Bhagwati and Hansen (1973) and Falvey (1978). Thus, the novelty of the current work lies in formally introducing a black market into the recent line of explicitly monetary international finance models dealing with the consequences of foreign exchange controls. It should also be mentioned that the current work is related to Kaminsky (n.d.) where an analysis of capital controls in an economy with a black market is conducted. Such syntheses would seem important to undertake given the prevalence of foreign exchange and capital controls in black market settings. ${ }^{1}$

\section{The representative agent's optimization problem}

Imagine a small open economy with a life span of two periods that has adopted a fixed exchange rate system. The government of this economy has

\footnotetext{
${ }^{1}$ The current analysis of black markets should also have a direct application to work on import quotas by Djajic (n.d.).
} 
imposed foreign exchange controls. Private agents have the option, however, of evading the government's foreign exchange restrictions by purchasing foreign currency illegally on a black market. The economy is inhabited by a representative agent whose goal is to maximize his lifetime utility, $U(\cdot)$, as specified by

$$
U(\cdot)=\sum_{t=1}^{2} \rho^{t-1}\left[U\left(X^{t}\right)+V\left(Z^{t}+\bar{Z}^{t}\right)\right]
$$

where $\rho$ is his subjective discount factor, and $X^{t}$ and $Z^{t}+\bar{Z}^{t}$ are his period-t consumption of an exported and imported good.

The representative agent has four sources of income in any given period, say $t$. First, in each period $t$ the individual is endowed with a certain quantity of the exported good $\bar{X}^{t}$, and the imported good, $\bar{Z}^{t}$. The exported good sells in world markets in period $t$ at the world terms of trade $p^{* t}$, by which is meant the relative price of imports in terms of exports. Second, the agent earns profits from the ownership of an illegal firm which sells foreign exchange on the black market. The profits of this firm in period $t$ amount in real, or export denominated, terms to $v^{t}$. Third, the agent gets a transfer payment $\tau^{t}$, from the domestic government in each period $t$. Fourth, he receives the interest and principal $\left(1+r^{* t-1}\right) b^{t-1}$ on any period-t-1 investment in export denominated bonds, $b^{t-1}$, he may have undertaken which pay the internationally determined real rate of return, $r^{* t-1}$.

All transactions in the model must be consummated using money: in particular domestically produced commodities must be purchased with domestic currency, denoted in real (or export denominated) terms by $m^{t}$, and foreign goods with foreign cash, $m^{* t}$. A time profile of the individual's life in period $t$ will now be given which highlights the circulation and role of money in the model. The presentation is brief since the sequencing of monetary transactions is similar to that adopted by Helpman (1981). The representative agent enters period $t$ with a certain amount of domestic and foreign money left over from the previous period $t-1$. At the beginning of period $t$ the individual receives in domestic currency the income from his period-t-1 sales of the imported and exported good, a dividend payment arising from the operation of his black market firm during the previous period, and a transfer payment from the government. He then enters the international bond-cum-foreign exchange market, redeems the bonds he bought during the previous period, purchases new bonds, and allocates his remaining holdings of cash between domestic and foreign currency. Since there are foreign exchange controls in place the maximum amount of foreign exchange he can legally acquire is $\tilde{m}^{* 1}$. This legal quota of foreign currency can be purchased at the official fixed exchange rate of $\bar{e}$ units of domestic money per unit of foreign money. Any purchases of foreign exchange, $m^{* t}-\tilde{m}^{* t}$, over this ceiling 
level must be bought illegally at the black market exchange rate, $s^{t}$. The agent's budget constraints for the two periods can thus be written (in export denominated terms) as

$$
\begin{aligned}
m^{1}+\tilde{m}^{* 1}+\left(s^{1} / \vec{e}\right)\left(m^{* 1}-\tilde{m}^{* 1}\right)+ & b^{1}=\tau^{1} \\
m^{2}+\tilde{m}^{* 2}+\left(s^{2} / \bar{e}\right)\left(m^{* 2}-\tilde{m}^{* 2}\right)= & \left(P^{1} / P^{2}\right)\left[\bar{X}^{1}+\left(P_{1}^{1} / P^{1}\right) \bar{Z}^{1}+v^{1}\right]+\tau^{2} \\
& +\left(P^{1} / P^{2}\right)\left[m^{1}-X^{1}-\left(P_{1}^{1} / P^{1}\right) \bar{Z}^{1}\right] \\
& +\left(P^{* 1} / P^{* 2}\right)\left(s^{2} / \vec{e}\right)\left[m^{* 1}-p^{* 1} Z^{1}\right] \\
& +\left(1+r^{*}\right) b^{1}
\end{aligned}
$$

where $P_{1}^{t}$ and $P^{t}$ are the period- $t$ domestic nominal prices for importables and exportables, and similarly $P^{* t}$ is the foreign currency price for the exported good. The formulation of these budget constraints reflects the assumption that foreign residents can acquire as much domestic currency as they desire at the official exchange rate, $\bar{e}$, in order to purchase domestic exportables implying the law of one price holds for these goods so that $P^{t}=\bar{e} P^{* t}$. Due to the presence of foreign exchange controls the law of one price does not have to hold - at the official exchange rate - for imports.

During the remainder of the period the individual purchases his consumption quantities of the exported and imported goods using his holdings of domestic and foreign currency while obeying the cash-in-advance constraints

$$
X^{t}+\left(P_{\mathrm{l}}^{t} / P^{t}\right) \bar{Z}^{t} \leqq m^{t} \quad \text { and } \quad p^{* t} Z^{t} \leqq m^{* t} \quad \forall t=1,2 .
$$

The specification of these constraints assumes that the agent satisfies his demand for goods from domestic sources first. The individual then enters period $t+1$ with any money he has left over and the process begins again.

The agent's goal in life is to choose $X^{t}, Z^{t}, m^{t}, m^{* t}$, for $t=1,2$ and $b^{1}$ to maximize $U$, as given by (1), subject to the constraints (2), (3) and (4). It should briefly be mentioned here a salient feature of cash-in-advance models is that, provided (domestic and foreign) nominal interest rates are positive, an assumption which will be made here, the individual will always choose to have the cash-in-advance constraints hold as strict equalities, since bonds then dominate money as an abode of purchasing so that it does not pay to hold excess cash balances. The upshot of this maximization problem is summarized by the following efficiency conditions:

$$
\begin{aligned}
& V_{1}\left(Z^{t}+\bar{Z}^{t}\right)=\left[1+\left(s^{t}-\bar{e}\right) / \bar{e}\right] p^{* t} U_{1}\left(X^{t}\right), \quad t=1,2, \\
& U_{1}\left(X^{1}\right)=\left(1+r^{*}\right) \rho U_{1}\left(X^{2}\right) .
\end{aligned}
$$


Eq. (5) describes how the agent should optimally divide his period-t expenditure on consumption between imported and exported goods. In an economy with both foreign exchange restrictions in place and a functional black market operating during period $t$ a wedge in the amount $\left[1+\left(s^{t}-\bar{e}\right) / \bar{e}\right]$ separates the period- $t$ marginal rate of substitution between import and export consumption, $V_{1}\left(Z^{t}+\bar{Z}^{t}\right) / U_{1}\left(X^{t}\right)$, from equality with the world terms of trade $p^{* t}$. It is easy to see that in the foreign exchange controlled-cumblack market economy $\left[1+\left(s^{t}-\bar{e}\right) / \bar{e}\right] p^{* t}$ is the effective domestic relative price for the imported good so that $P_{1}^{t} / P^{t}=\left[1+\left(s^{t}-\bar{e}\right) / \bar{e}\right] p^{* t}$. Recall that in order to purchase an additional unit of the imported good the agent must first acquire an additional $P_{l}^{* t}$ unit of the foreign currency. Since there are (quasi) effective foreign exchange controls in place this must be bought on the black market for a domestic currency price of $s^{t} P_{1}^{* t}$. In real terms this is worth $\left(s^{t} / \bar{e}\right) p^{* t}=\left[1+\left(s^{t}-\bar{e}\right) / \bar{e}\right] p^{* t}$ units of the exported good. Note that the term $\left[\left(s^{t}-\bar{e}\right) / \bar{e}\right] p^{* t}$ measures the black market premium for foreign exchange and operates to raise the domestic relative price for imports above the world level in exactly the same manner as a tariff would. Finally (6) is the familiar intertemporal efficiency condition characterizing the agent's consumptionsavings decision. ${ }^{2}$

The agent's optimization problem implies that his compensated demand functions for the imported and exported goods will have the following forms:

$$
Z^{t}+\bar{Z}^{t}=Z^{t}\left(p^{* 1}\left(1+\eta^{1}\right), p^{* 2}\left(1+\eta^{2}\right) /\left(1+r^{*}\right), 1 /\left(1+r^{*}\right), U\right)+\bar{Z}^{t}
$$

and

$$
X^{t}=X^{t}\left(p^{* 1}\left(1+\eta^{1}\right), p^{* 2}\left(1+\eta^{2}\right) /\left(1+r^{*}\right), 1 /\left(1+r^{*}\right), \boldsymbol{U}\right),
$$

where $\eta^{t} \equiv\left(s^{t}-\vec{e}\right) / \bar{e}$ is the (proportionate) black market premium on foreign exchange. The separable form of the utility function guarantees that substitutability and normality prevail. Thus, for example $Z_{1}^{1}<0$, and $Z_{2}^{1}, Z_{3}^{1}, Z_{4}^{1}>0$, where $Z_{j}^{1}$ is the derivative of $Z^{1}(\cdot)$ with respect to its $j$ th argument. It is needless to say that the agent's level of welfare, $U$, in general equilibrium is dependent on such things as his endowment of the export and import goods, the terms of trade, the world real interest rate, the extent of foreign exchange controls and the cost of operating a black market. The nature of this dependence is discussed in fuller detail later on.

\section{The black market for foreign exchange}

The black market is run by a representative firm - dubbed the black marketeer - whose goal is to maximize its profits, $v$. While the black

\footnotetext{
${ }^{2}$ Greenwood and Kimbrough (1986) and Kaminsky (n.d.) show that in an economy with capital controls a tariff-like wedge will be present in the first-order condition associated with the agent's consumption-saving decision.
} 
marketeer has the ability to channel foreign currency away from the official foreign exchange market to the black market this diversion can only be done at an increasing real resource cost borne in terms of the exported good. The black market firm's period- $t$ choice problem is shown below, with the volume of illegal foreign exchange sales, $m^{* t}-\tilde{m}^{* t}$, being its decision variable,

$$
\max v^{t}=\left[\left(s^{t}-\tilde{e}\right) / \bar{e}\right]\left(m^{* t}-\tilde{m}^{* t}\right)-\phi\left(m^{* t} / p^{* t}-\tilde{m}^{* t} / p^{* t}\right)
$$

[with $\phi(0)=\phi_{1}(0)=0$ ] where the increasing convex cost function $\phi(\cdot t)$ describes the black market production process. ${ }^{3}$ The first-order condition arising from this maximization problem is

$$
\left(s^{t}-\bar{e}\right) / \vec{e}=\phi_{1}\left(m^{* t} / p^{* t}-\tilde{m}^{* t} / p^{* t}\right) / p^{* t} \quad \forall t=1,2
$$

The left-hand side of this equation represents the net real marginal revenue obtained from diverting an additional (real) unit of foreign currency away from the official foreign exchange market (where it can be purchased from the equivalent of one unit of the exported good) to the black market (on which it commands a price of $s^{t} / \bar{e}$ units of exports). The right-hand side of the above equation represents the real marginal cost of an additional sale of foreign exchange on the black market.

From the firm's choice problem the following supply curve for black market foreign exchange can be obtained:

$$
m^{* t} / p^{* t}-\tilde{m}^{* t} / p^{* t}=Z^{B}\left(\eta^{t} p^{* t}\right) \equiv \phi_{1}^{-1}\left(\eta^{t} p^{* t}\right)
$$

[where $\eta^{t} \equiv\left(s^{t}-\bar{e}\right) / \bar{e}$ and $\left.Z_{1}^{B}=1 / \phi_{11}>0\right]$. Note, not surprisingly, that the supply of foreign exchange in the black market is an increasing function of the black market premium, $\eta^{t} p^{* t}$.

\section{The economy's general equilibrium}

The economy under consideration is effectively composed of four agents: a consumer, a firm, a black marketeer, and the government. The government, like the 'stand in' consumer, must satisfy a budget constraint. Its budget constraints for the first and second periods are

$$
m_{\mathrm{s}}^{1}=\tau^{1}+b_{\mathrm{R}}^{1} \quad \text { and } \quad m_{\mathrm{s}}^{2}=\tau^{2}+\left(P^{1} / P^{2}\right) m_{\mathrm{s}}^{1}-b_{\mathrm{R}}^{1}\left(1+r^{*}\right)
$$

where $m_{\mathrm{s}}^{t}$ is the real supply of money in period $t, \tau^{t}$ plays the role of period- $t$

\footnotetext{
${ }^{3}$ The normalization of $m^{* t}$ and $\tilde{m}^{* t}$ by $p^{* t}$ in the function $\phi(\cdot t)$ was done for technical convenience only and is devoid of any implications for the paper's conclusions.
} 
domestic credit and $b_{\mathbb{R}}^{1}$ represents the government's acquisition of interestbearing reserves in the first period.

Next, equilibrium in the domestic money market implies that the demand and supply for money in each period must be equal. Thus, taking tally of individuals' and legal and illegal enterprises' holdings of money at the time the financial market closes yields

$$
m^{t}+m_{\mathrm{F}}^{t}+v^{t}+\phi(\cdot t)=m_{\mathrm{s}}^{t}
$$

where $m_{\mathrm{F}}^{t}$ is the rest-of-the-world's (the foreign country's) period-t real holdings of domestic cash balances. ${ }^{4}$ Now recall that the cash-in-advance constraints will hold as strict equalities so long as the nominal interest rates are positive, so from (4) $m^{t}=X^{t}+\left(P_{\mathrm{l}}^{t} / P^{t}\right) \bar{Z}^{t}$. If, as will be assumed, foreign residents are solving an analogous optimization problem, except without the foreign exchange restriction, then $m_{\mathrm{F}}^{t}=X_{\mathrm{F}}^{t}$ where $X_{\mathrm{F}}^{t}$ is the foreign consumption of the domestic exported good. Hence, (12) can be rewritten as

$$
\bar{X}^{t}+\left(P_{\mathrm{l}}^{t} / P^{t}\right) \bar{Z}^{t}+v^{t}=m_{\mathrm{s}}^{t}
$$

where the left-hand side of (13) follows from the fact that the domestic exported goods market must clear each period so that $X^{t}+X_{\mathrm{F}}^{t}+\phi(\cdot t)=\bar{X}^{t}$. An expression of the current balance of payments can be obtained from (11) and (13). Specifically,

$$
b_{\mathrm{R}}^{1}=\bar{X}^{1}+\left(P_{\mathrm{I}}^{1} / P^{1}\right) \bar{Z}^{1}+v^{1}-\tau^{1} .
$$

Finally, in the model international trade must balance intertemporally, or ${ }^{5}$

$$
p^{* 1} Z^{1}+X^{1}+\frac{p^{* 2} Z^{2}+X^{2}}{\left(1+r^{*}\right)}=\bar{X}^{1}-\phi(\cdot 1)+\frac{\bar{X}^{2}-\phi(\cdot 2)}{\left(1+r^{*}\right)} .
$$

How foreign exchange controls in the presence of a black market impinge on the model's general equilibrium has yet to be specified; this is the subject of the next section.

${ }^{4}$ Note that at the time the financial market closes in period $t$ the black marketeer will have made sales in domestic currency in the amount $\left[\left(s^{t}-\bar{e}\right) / \bar{e}\right]\left[m^{* t}-\tilde{m}^{* t}\right]$ on which he retains $v^{t}$ in profits with the remaining amount, $\phi(\cdot t)$, having been distributed to (and in the current possession of) domestic firms for goods which are used as inputs into the black market production process.

${ }^{5} \mathrm{Eq}$. (15) is an implication and not an assumption of the model. It can be derived in the following standard but tedious manner: first, discount eq. (3) by $\left(1+r^{*}\right)$ and then add it to (2). Second, in the obtained expression eliminate the transfer payment terms through the use of (11), the resulting money supply terms by utilizing (13), the induced black market profit terms via (8), and finally the money demand terms by (4). 


\section{Foreign exchange controls in a black market setting}

Suppose that the government has temporarily instituted a system of foreign exchange controls in the first period. Furthermore, assume that there is a fully operational black market functioning in this period. Now, the imported goods market must clear domestically in the first period in the sense that the demand for imports, $Z^{1}$, must equal the combined supply of imports from legal and black market sources, $\tilde{m}^{* 1} / p^{* 1}+\left[m^{* 1}-\tilde{m}^{* 1}\right] / p^{* 1}$. Thus, the following first-period import market clearing condition must hold:

$$
Z^{1}\left(p^{* 1}\left(1+\eta^{1}\right), p^{* 2} /\left(1+r^{*}\right), 1 /\left(1+r^{*}\right), U\right)=\tilde{m}^{* 1} / p^{* 1}+Z^{B}\left(\eta^{1} p^{* 1}\right)
$$

In response to various shocks to the economy the domestic market price for first-period imports, $p^{* 1}\left(1+\eta^{1}\right)$, must adjust in order to maintain equilibrium in the imported goods market. ${ }^{6}$

To see this, and as an aid in understanding how an economy with foreign exchange controls and a black market operates, consider the impact of an anticipated increase in the agent's second-period endowment of the exported good, $\bar{X}^{2}$. As a consequence of this beneficial change in the second-period endowment of exports, the representative agent immediately realizes an improvement in his welfare $U$ in the amount [cf. eqs. (1), (5), (6) and (15)],

$$
\mathrm{d} U / \mathrm{d} \bar{X}^{2}=\left(1 /\left(1+r^{*}\right)\right) U_{1}\left(X^{1}\right)>0 .
$$

This improvement in the agent's real welfare will of course lead to increases in his demand for current imports, and since this market must clear domestically the equilibrating response in general will be both a higher price for and quantity supplied of imports. Specifically, from (16) and (17) it can be seen that

$$
\mathrm{d}\left[p^{* 1}\left(1+\eta^{1}\right)\right] / \mathrm{d} \bar{X}^{2}=-\left(1 /\left(1+r^{*}\right)\right) \mu_{Z}^{1} /\left[p^{* 1}\left(1+\eta^{1}\right)\left(Z_{1}^{1}-Z_{1}^{B}\right)\right]>0
$$

and

$$
\mathrm{d} Z^{1} / \mathrm{d} \bar{X}^{2}=Z_{1}^{B}(\cdot 1) \mathrm{d}\left[p^{* 1}\left(1+\eta^{1}\right)\right] / \mathrm{d} \bar{X}^{2}>0,
$$

where $\mu_{Z}^{1} \equiv p^{* 1}\left(1+\eta^{1}\right) U_{1}\left(X^{1}\right) Z_{4}^{1}$ is the marginal propensity to consume firstperiod imports. Note that the implied rise in today's black market premium on foreign exchange, $\eta^{1}$, is larger the bigger the marginal propensity to consume first period imports is, and smaller the greater is $Z_{1}^{1}-Z_{1}^{B}$ which represents the substitution effect of a change in $p^{* 1}\left(1+\eta^{1}\right)$ on the excess demand for current import consumption.

\footnotetext{
${ }^{6}$ Similarly, in an economy with capital controls the black market premium on capital account transactions must adjust to equilibrate the domestic demand and supply for savings - see Kaminsky (n.d.).
} 


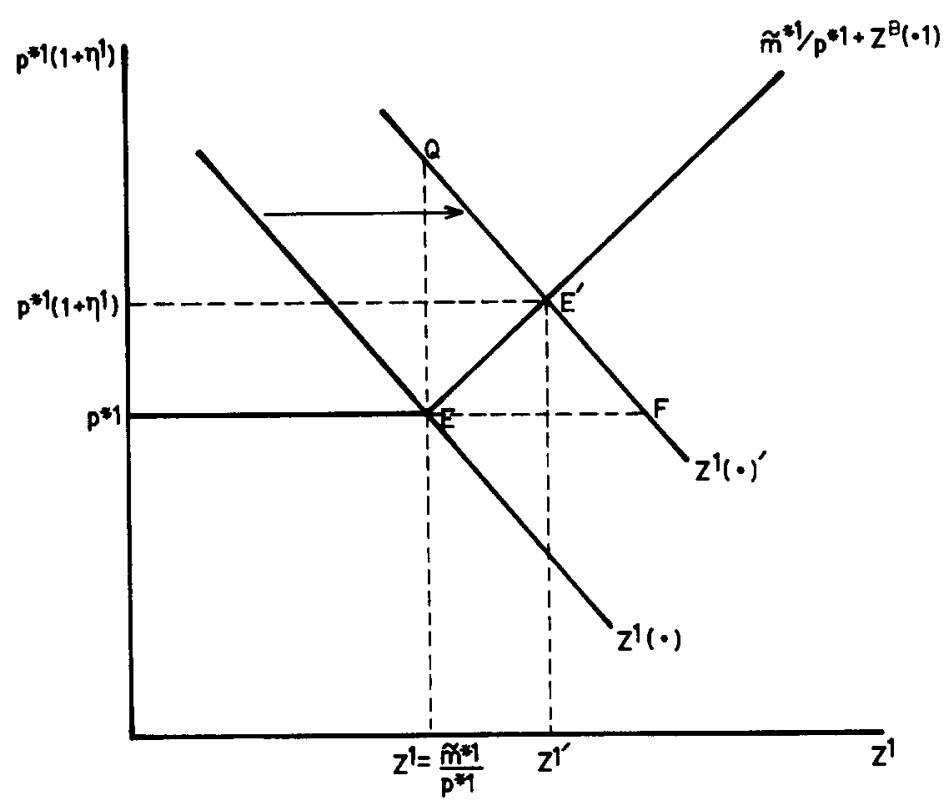

Fig. 1

The above comparative statics exercise has a simple graphical portrayal which is shown in fig. 1 . The initial equilibrium is represented by the point $E$ where the demand and supply functions, $Z^{1}(\cdot)$ and $\tilde{m}^{* 1} / p^{* 1}+Z^{B}(\cdot 1)$, respectively, intersect. The controls are just binding in this initial position. The improvement in the agent's welfare due to the anticipated rise in his secondperiod endowment of exported good shifts the demand curve to the right to the position shown by $Z^{1}(\cdot)^{\prime}$. It can be seen, from the new equilibrium point $E^{\prime}$, that as a result both the price and quantity of imports increase. It is interesting to compare the results just obtained to those that would occur in the above economy, first without a black market, and second, in the absence of foreign exchange controls. When there is not an operational black market the supply curve for current imports would be perfectly inelastic at the quantity $\tilde{m}^{* 1} / p^{* 1}$. Consequently, an upward movement in the representative agent's second-period endowment of exports would lead solely to an increase in $p^{* 1}\left(1+\eta^{1}\right)$ with there being no accompanying shift in $Z^{1}$, as is shown by the equilibrium point $Q$. In the absence of foreign exchange controls the supply curve for current imports is perfectly elastic at the world terms of trade, $p^{* 1}$. Here the improvement in the agent's second-period income level leads to a new equilibrium at $F$ which is characterized by an increase in firstperiod import consumption, with there being no accompanying change in the domestic relative price of imports. Thus, perhaps not surprisingly, the introduction of a black market into an economy with foreign exchange 


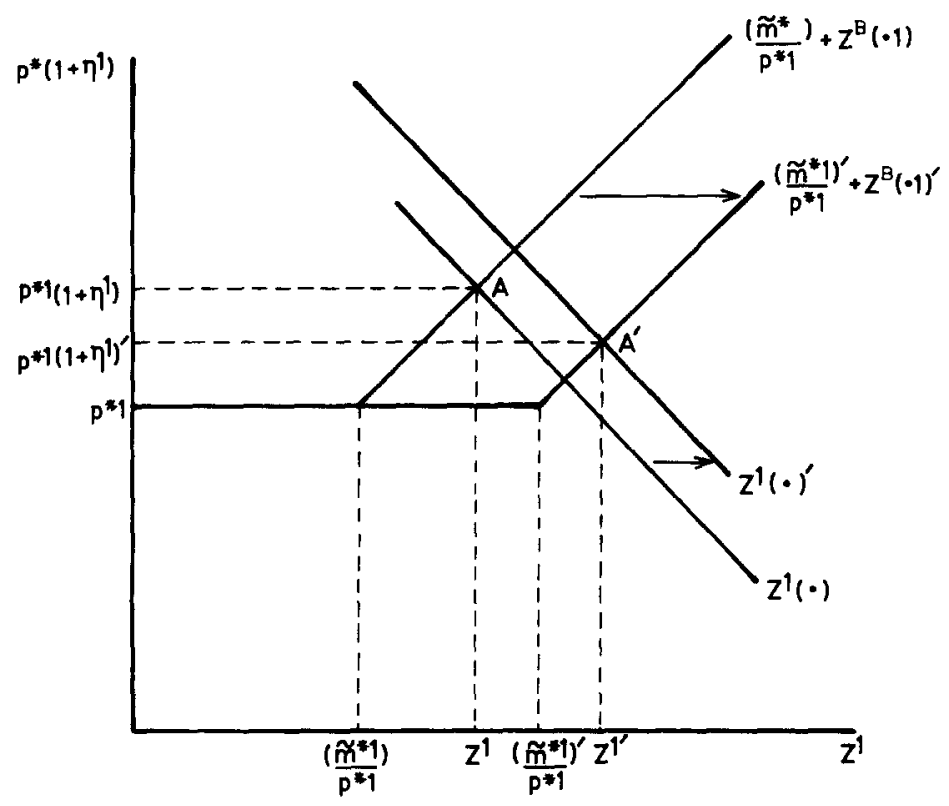

Fig. 2

controls creates a hybrid economy which is a cross between the 'pure' foreign exchange controlled and free economies.

Next consider the impact of relaxing the first-period exchange controls by the amount $\mathrm{d} \tilde{m}^{* 1}$. It is easy to see that this will result in the current supply of imports increasing by the amount $\left(1 / p^{* 1}\right) \mathrm{d} \tilde{m}^{* 1}$, ceteris paribus, as shown in fig. 2. As a result of the liberalization in the level of foreign exchange controls the agent realizes a welfare gain in the amount $\eta^{1} U_{1}\left(X^{1}\right) \mathrm{d} \tilde{m}^{* 1}$. This causes the demand for imports, other things equal, to rise by $\left(1 / p^{* 1}\right)\left[\eta^{1} /\right.$ $\left.\left(1+\eta^{1}\right)\right] \mu_{Z}^{1} \mathrm{~d} \tilde{m}^{* 1}$ which is also portrayed in fig. 2 . Since at the initial relative price for imports supply increases more than demand, the price of imports falls so as to clear the market. Note that the consumption of imports increases. These facts are represented in fig. 2 by the change in the equilibrium point from $A$ to $A^{\prime}$.

The drop in the current price of imports causes the balance of payments in the first period to deteriorate since it causes a reduction in the demand for money. Formally, from (14), and an application of the standard envelope theorem to the profit function $v(\cdot 1)$ as defined by $(8)$, it follows that ${ }^{7}$

$$
\mathrm{d} b_{\mathbf{R}}^{1} / \mathrm{d} \tilde{m}^{* 1}=\left[Z^{1}+\left(m^{* 1}-\tilde{m}^{* 1}\right) / p^{* 1}\right] \mathrm{d}\left[p^{* 1}\left(1+\eta^{1}\right)\right] / \mathrm{d} \tilde{m}^{* 1}<0 .
$$

${ }^{7}$ Consider again the first comparative statics exercise where the impact of an improvement in the economy's second-period endowment of exports was studied. It is easy to see that this causes the economy's first-period balance of payments to improve since the resulting rise in relative price of current imports induces an increase in the demand for money. 
Finally, the change in the current trade balance, $t b^{1}=\bar{X}-X^{1}-p^{* 1} Z^{1}-$ $\phi(\cdot 1)$, in response to a liberalization of exchange controls is

$$
\begin{aligned}
\mathrm{d} t b^{1} / \mathrm{d} \tilde{m}^{* 1}=- & \left\{\eta^{1} \mu_{\mathrm{X}}^{1}+1+p^{* 1}\left(1+\phi_{1}(\cdot 1) / p^{* 1}\right) Z_{1}^{B}(\cdot 1) \mathrm{d}\left[p^{* 1}\left(1+\eta^{1}\right)\right] / \mathrm{d} \tilde{m}^{* 1}\right. \\
& \left.+X_{1}^{1} \mathrm{~d}\left[p^{* 1}\left(1+\eta^{1}\right)\right] / \mathrm{d} \tilde{m}^{* 1}\right\} \gtrless 0,
\end{aligned}
$$

where $\mu_{\mathrm{X}}^{1} \equiv X_{4}^{1} U_{1}\left(X^{1}\right)$ is the marginal propensity to consume first-period exports. The sign of the above expression is in general ambiguous. There are four terms to consider on the right-hand side of the above expression. The first term illustrates the rise in the agent's current consumption of the exported good stimulated by the increase in his welfare level. This has a negative impact on the trade balance. The second term shows the direct oneto-one deleterious effect on the trade balance associated with the increase in imports induced by the liberalization in exchange controls. The drop in the current price of imports results in fewer goods being channeled through the black market and this operates to improve the trade balance - both directly via the fall in the volume of illegal imports and indirectly due to the fact that the resource cost associated with operating a black market is reduced - as is portrayed by the third term. Finally, the fall in the price of current imports retards export consumption and, as the last term illustrates, this works to improve the trade balance. It turns out that starting from an initial position of free trade, however, a slight restriction in the level of foreign exchange domestic residents can hold will unambiguously improve the trade balance. ${ }^{8,9}$ Thus, an important observation can be drawn from the above comparative statics exercise. By temporarily imposing a system of foreign exchange controls a country may improve both its trade balance and balance of payments, which is presumably one reason why foreign exchange controls are so popular. The imposition of foreign exchange controls, however, is associated with a loss in private sector welfare. ${ }^{10}$

\footnotetext{
${ }^{8}$ This is most easily seen by noting from (15) that the first-period trade balance can also be written as $t b^{1}=-\left[1 /\left(1+r^{*}\right)\right]\left(\bar{X}^{2}-X^{2}-p^{* 2} Z^{2}\right)$. Since, when starting from a position of free trade, there is no income effect associated with a slight restriction in the level of foreign currency domestic residents can hold, only the positive substitution effect on second-period export and import consumption associated with the rise in the domestic price of current imports is operational, which tends to move the current trade balance into surplus.

${ }^{9}$ Once again consider the effect of an upward movement in the economy's second-period endowment of exports, as was done in the first comparative statics exercise. Here today's trade balance unambiguously deteriorates since both current export and import [cf. (18)] consumption increases, while the resource costs of operating the black market rise as well. This result is similar to that which obtains in economies without foreign exchange controls - see Greenwood (1983) and Svensson and Razin (1983).

${ }^{10}$ There could be distortions present in the domestic economy which foreign exchange controls work to eliminate and thereby improve welfare. The task for proponents of such controls should be to identify the distortions and explain why they are likely to dominate alternative commercial policies. Needless to say, most of the policy debate has not been oriented along these lines.
} 


\section{Black markets and economic welfare}

An obvious question which comes to mind is how the presence of a black market in an economy with foreign exchange controls affects economic welfare. The answer in the current setting is ambiguous, being crucially dependent upon the government's reaction to the leakage of foreign exchange through the black market. This point will be demonstrated through the use of two examples. To begin with, suppose that the government sets its ceiling levels on private agents' holding of foreign exchange disregarding the possibility of illegal activity. In this circumstance the existence of a black market will improve welfare even though its operation incurs a real resource cost. To see this notice that the real general equilibrium of the decentralized competitive foreign exchange controlled economy with a functioning black market can be compactly summarized as the unique solution to the following programming problem with $X^{1}, X^{2}, Z^{1}$ and $Z^{2}$ being the decision variables: ${ }^{11}$

$$
\begin{gathered}
\max U\left(X^{1}\right)+V\left(Z^{1}+\bar{Z}^{1}\right)+\rho\left[U\left(X^{2}\right)+V\left(Z^{2}+\bar{Z}^{2}\right)\right], \quad \text { s.t. } \\
\begin{aligned}
p^{* 1} Z^{1}+X^{1}+\frac{p^{* 2} Z^{2}+X^{2}}{\left(1+r^{*}\right)}= & \bar{X}^{1}-\phi\left(Z^{1}-\tilde{m}^{* 1} / p^{* 1}\right) \\
& +\frac{\bar{X}^{2}-\phi\left(Z^{2}-\tilde{m}^{* 2} / p^{* 2}\right)}{\left(1+r^{*}\right)}
\end{aligned}
\end{gathered}
$$

Now, without an operational black market in place $p^{* t} Z^{t}=\tilde{m}^{* t}$ for each period $t$. Clearly, this restriction is in the feasible set of solutions to the above programming problem but, in general, will not be a characteristic of the optimal solution. Thus, the welfare level of the foreign exchange controlled economy with a black market will be at least as high as the welfare level of the same economy without a black market. The intuition behind this result is straightforward. Giving private agents the option to trade on a black market increases their level of welfare since it allows them to partially evade the quantitative restrictions levied on their trading opportunities by the government. ${ }^{12}$ In the standard trade literature Falvey

\footnotetext{
${ }^{11}$ That the outcomes of decentralized competitive economy can often be mimicked by a simple programming problem is a well known fact. See Negishi (1960) for the formal details in a general setting. Note that the decentralized monetary economy's real allocations, $X^{1}, X^{2}, Z^{1}$ and $Z^{2}$ are determined by the system of four equations given by (5), (6) and (15), with the term $\left(s^{t}-\bar{e}\right) / \bar{e}$ in (5) being replaced by $\phi_{1}\left(Z^{t}-\tilde{m}^{* t} / p^{* t}\right) / p^{* t}$ in accordance with (9) and (4). This set of equations also describes the solution to the problem (P1).

${ }_{12}^{2}$ Presumably, the government can influence the private cost of black market activity. To investigate this observation further, let the period- $t$ black market transaction cost function now be given by $\phi^{t}=\phi\left(Z^{t}-\tilde{m}^{* t} / p^{* t}, c^{t}\right)$, with $\phi_{1}, \phi_{11}, \phi_{2}, \phi_{21}>0, \phi_{22}<0$, and where $c^{t}$ represents the level of policing activity by the government in this period. Enforcement also has costs, $\varphi^{t}$, given
} 
(1978) has demonstrated that smuggling improves welfare in the presence of import quotas for the same reason.

Now consider the alternative story describing the government's behavior. Specifically, imagine that the government is actively managing $\tilde{m}^{* 1}$ and $\tilde{m}^{* 2}$ while taking full account of the existence of a black market in the economy, so that some policy objective, say a target level for total first- and secondperiod imports, $\tilde{Z}^{1}$ and $\tilde{Z}^{2}$, will be obtained. This seems more realistic unless one believes that the policymaking process is fundamentally inept. To obtain the benchmark first-best policy for limiting imports imagine that the economy is run by a central planner who can dictate individual behavior. The central planner's goal is to maximize private-sector welfare (1) subject to the economy's intertemporal budget constraint (15), and the import restrictions as given by (19). This problem is shown below where the central planner is choosing values for $X^{1}, X^{2}, Z^{1}, Z^{2}, \tilde{m}^{* 1}$ and $\tilde{m}^{* 2}$,

$$
\begin{aligned}
& \max U\left(X^{1}\right)+V\left(Z^{1}+\bar{Z}^{1}\right)+\rho\left[U\left(X^{2}\right)+V\left(Z^{2}+\bar{Z}^{2}\right)\right], \quad \text { s.t. } \\
& \begin{aligned}
& p^{* 1} Z^{1}+X^{1}+\frac{p^{* 2} Z^{2}+X^{2}}{\left(1+r^{*}\right)}= \bar{X}^{1}-\phi\left(Z^{1}-\tilde{m}^{* 1} / p^{* 1}\right) \\
&+\frac{\bar{X}^{2}-\phi\left(Z^{2}-\tilde{m}^{* 2} / p^{* 2}\right)}{\left(1+r^{*}\right)}, \\
& Z^{t}=\tilde{Z}^{t} \quad \forall t=1,2 .
\end{aligned}
\end{aligned}
$$

The solution to this programming problem yields the unique first-best policy for attaining maximal societal welfare given the government's policy objective. Such a first-best policy may not be implementable in decentralized competitive equilibrium. Trivially, it can be seen that the central planner will choose not to operate a black market since the right-hand side of (15), or the present-value of the economy's endowment of the export good, is maximized when $\tilde{m}^{* t}$ is chosen so that $p^{* t} Z^{t}=\tilde{m}^{* t}$.

by the increasing convex cost function $\varphi^{t}=\varphi\left(c^{t}\right)$. The competitively behaving private sector takes the level of enforcement in each period as given and its behavior is again fully described by the solution to problem (P1), where the right-hand side of the constraint (15) should now be formulated as $\bar{X}^{1}-\phi\left(\cdot 1, c^{1}\right)-\varphi\left(c^{1}\right)+\left[\bar{X}^{2}-\phi\left(\cdot 2, c^{2}\right)-\varphi\left(c^{2}\right)\right] /\left(1+r^{*}\right)$. The government here is taken to choose $c^{1}$ and $c^{2}$ so as to suppress in a cost-efficient manner the volume of black market activity, an obvious metric of which is $\phi(\cdot 1)+\phi(\cdot 2) /\left(1+r^{*}\right)$. Its goal is to pick $c^{1}, c^{2}$ so as to minimize $\left\{\phi\left(Z^{1}-\tilde{m}^{* 1} / p^{* 1}, c^{1}\right)+\varphi\left(c^{1}\right)+\left[\phi\left(Z^{2}-\tilde{m}^{* 2} / p^{* 2}, c^{2}\right)+\varphi\left(c^{2}\right)\right] /\left(1+r^{*}\right)\right\}$ subject to $Z^{t}$ $=Z^{\prime}\left(X^{1}, \bar{X}^{2}, Z^{1}, \bar{Z}^{2}, p^{* 1}, p^{* 2}, r^{*}, \tilde{m}^{* 1}, \tilde{m}^{* 2}, c^{1}, c^{2}\right)$, where the functions $Z^{\prime}(\cdot)$ are taken to be those that solve the reformulated version of (P1). It's easy to see that private welfare is lowered by government policing of black market activity. This follows from the observation that if the private sector could choose $c^{1}$ and $c^{2}$ in the new version of $(\mathrm{P} 1)$ they would pick $c^{1}=c^{2}=0$. 
In the decentralized competitive economy the policymaker is regulating $\tilde{m}^{* 1}$ and $\tilde{m}^{* 2}$ so as to attain the target levels for imports, $\tilde{Z}^{1}$ and $\tilde{Z}^{2}$. Since now the government cannot dictate individuals' behavior it must manipulate these policy instruments so that it is in agents' own best interest to consume the target values for imports. Denote the efficient values for these policy instruments by $\tilde{m}_{Z}^{* 1}$ and $\tilde{m}_{Z}^{* 2} \cdot{ }^{13}$ Now, the outcomes of the decentralized competitive equilibrium can be obtained from a modified version of the problem (P1). Specifically, in the new programming problem $\tilde{m}_{Z}^{* 1}$ and $\tilde{m}_{Z}^{* 2}$ replace $\tilde{m}^{* 1}$ and $\tilde{m}^{* 2}$ in (15). Also, notice that the constraints (19) can actually be added to this new problem at no cost since $\tilde{m}_{Z}^{* 1}$ and $\tilde{m}_{Z}^{* 2}$ have been picked by the government to ensure that $Z^{1}$ and $Z^{2}$ are in fact equal to $\tilde{Z}^{1}$ and $\tilde{Z}^{2}$. Thus, the imposition of these constraints is in fact redundant. Clearly, the level of welfare attained in the decentralized economy with a black market is lower than that achieved in the centrally planned economy since in (P2) $\tilde{m}^{* 1}$ and $\tilde{m}^{* 2}$ are choice variables determined optimally so that $\phi(\cdot t)=0$ for all $t$ and will not have values (in general) equal to $\tilde{m}_{Z}^{* 1}$ and $\tilde{m}_{Z}^{* 2}$. For a given level of import restrictions, the decentralized economy incurs the deadweight cost of running a black market, $\phi(\cdot 1)+\phi(\cdot 2) /\left(1+r^{*}\right){ }^{14}$ Note that each individual in the competitive equilibrium avails himself of the opportunity to participate on the black market because from his perspective it is optimal to do so, as problem (P1) in this section clearly illustrated. From the social perspective this is not the case because any leakage of imports into the economy that the black market allows is met by a tightening of exchange controls so that the government's policy target is still met. The individual fails to internalize this last aspect of the problem into his decision-making. Bhagwati and Hansen (1973) have noted for similar reasons, in the real trade literature, that smuggling in the presence of tariffs can

\footnotetext{
${ }^{13}$ The government presumably should pick the policy instruments $\tilde{m}_{Z}^{* 1}$ and $\tilde{m}_{Z}^{* 2}$ so that the target levels for imports, $\tilde{Z}^{1}$ and $\tilde{Z}^{2}$, are attained optimally. Define $V=V\left(\bar{X}^{1}, \bar{X}^{2}, \bar{Z}^{1}, \bar{Z}^{2}, p^{* 1}\right.$, $\left.p^{* 2}, r^{*}, \tilde{m}_{Z}^{* 1}, \tilde{m}_{Z}^{* 2}\right)$ as the value function associated with the problem (P1). Also, note that the solution to this problem implies that $Z^{t}$ can be written as the following function: $Z^{t}=Z^{t}\left(\bar{X}^{1}, \bar{X}^{2}\right.$, $\left.\bar{Z}^{1}, \bar{Z}^{2}, p^{* 1}, p^{* 2}, r^{*}, \tilde{m}_{Z}^{* 1}, \tilde{m}_{Z}^{* 2}\right)$. The government's goal should be to choose $\tilde{m}_{Z}^{* 1}$ so as to maximize $V(\cdot)$ subject to the constraint that $Z^{\prime}(\cdot)=Z^{\prime}$ for all $t$. Essentially, one has a dominant player game here with the government playing the role of leader, fully cognizant and capitalizing on the fact that its behavior influences the private sector's import reaction functions, while atomistic private sector agents take the government's policy as given.

${ }^{14}$ Once again, an interesting question is how government regulation of black market activity affects these results. Using the framework and notation developed in footnotes 12 and 13 , now the government's natural objective in its role as the dominant player in the economy is to choose $\tilde{m}_{Z}^{* 1}, \tilde{m}_{Z}^{* 2}, c^{1}$ and $c^{2}$ so as to maximize $V\left(\bar{X}^{1}, X^{2}, Z^{1}, Z^{2}, p^{* 1}, p^{* 2}, r^{*}, \tilde{m}_{Z}^{* 1}, \tilde{m}_{Z}^{* 2}, c^{1}, c^{2}\right)$ subject to $Z^{\prime}\left(\bar{X}^{1}, \bar{X}^{2}, \bar{Z}^{1}, \bar{Z}^{2}, p^{* 1}, p^{* 2}, r^{*}, \tilde{m}_{Z}^{* 1}, \tilde{m}_{Z}^{* 2}, c^{1}, c^{2}\right)=\bar{Z}^{t}$ where once again $V(\cdot)$ and $Z^{\prime}(\cdot)$ represent the value function and import reaction functions associated with the appropriately reformulated version of problem (P1). Clearly, by policing black market activity the government can improve the private sector's welfare since it now has the additional control variables $c^{1}$ and $c^{2}$. Essentially, the government can pick $c^{1}$ and $c^{2}$ so as to influence the private costs of running the black market so as to optimally minimize in a welfare sense the deadweight cost associated with its operation.
} 
reduce welfare if the government is using the tariffs to achieve certain policy objectives such as a target level of domestic production for the import good.

\section{Conclusions}

A choice-theoretic model of a small open economy has been developed to study the impact of foreign exchange controls in settings where black markets are present. It was found in such environments that the imposition of foreign exchange controls tends to raise the domestic relative price of imports above the world level in exactly the same manner as a tariff would. For a given level of exchange controls a black market mitigated the effect of such quantitative restrictions on the domestic relative price and consumption of imports. While foreign exchange controls may improve the trade balance and balance of payments of an economy even with black markets, they unambiguously lower economic welfare. Finally, the welfare implications of a black market were found to be ambiguous and contingent upon the government's reaction to its presence. For instance, if the government ignores the existence of the black market then the private sector can partially evade the government's foreign exchange restrictions and potentially improve its welfare. Alternatively, if the government reacts to the leakage of foreign exchange through the black market by tightening its foreign exchange restrictions so as to maintain some policy objective, such as regulating the total volume of imports, then a black market may reduce welfare.

\section{References}

Bhagwati, J. and B. Hansen, 1973, Theoretical analysis of smuggling, Quarterly Journal of Economics LXXXVII, 172-187.

Djajic, S., n.d., Temporary import quota and the current account, Journal of International Economics, forthcoming.

Falvey, R.E., 1978, A note on preferential and illegal trade under quantitative restrictions, Quarterly Journal of Economics XCII, 175-178.

Greenwood, J., 1983, Expectations, the exchange rate and the current account, Journal of Monetary Economics 12, 543-569.

Greenwood, J. and K.P. Kimbrough, 1985, Capital controls and fiscal policy in the world economy, Canadian Journal of Economics XVIII, 743-765.

Greenwood, J. and K.P. Kimbrough, 1986, An investigation in the theory of foreign exchange controls, Working paper no. 86-13 (Department of Economics, Duke University, Durham, NC). Canadian Journal of Economics, forthcoming.

Helpman, E., 1981, An exploration in the theory of exchange rate regimes, Journal of Political Economy 89, 865-890.

Kaminsky, G.L., n.d., The black market and its effects on welfare and on the current account, International Economic Review, forthcoming.

Kowalczyk, C., 1985, Exchange controls in a semi-small cash in advance economy, Unpublished manuscript (Department of Economics, University of Rochester, Rochester, NY).

Negishi, T., 1960, Welfare economics and existence of an equilibrium for a competitive economy, Metroeconomica XII, 92-97.

Svensson, L.E.O. and A. Razin, 1983, The terms of trade and the current account: The Harberger-Laursen-Metzler effect, Journal of Political Economy, 97-125. 